\title{
A POTÊNCIA INSTITUINTE NO PROJETO "EXERCENDO CIDADANIA"1
}

\author{
Fabiana Davel Canal \\ Gilead Marchezi Tavares
}

\begin{abstract}
RESUMO. As Penas e Medidas Alternativas (PMAs) são cada vez mais utilizadas pelo sistema jurídico brasileiro. Diante desse contexto, a Vara de Execuções de Penas e Medidas Alternativas do Espírito Santo estabeleceu um convênio com Prefeitura Municipal de Vitória que oferece um curso de formação em Direitos Humanos, intitulado "Exercendo Cidadania" como forma de cumprimento das PMAs. Este artigo é resultado da análise preliminar de uma pesquisa que tem como objetivo analisar a execução das PMAs no município de Vitória-ES, com atenção especial para o curso em questão. O diário de campo foi o principal instrumento metodológico, confeccionado pelas vivências no curso de outubro a novembro de 2010. Ficamos atentos aos movimentos que nos indicavam como o apenado entende/vive/pensa a PMA,observando as formas rígidas, instituídas de efetivação das mesmas, mas também - e isso que tentamos dar visibilidade - a potência instituinte do curso.
\end{abstract}

Palavras-chave: Penas alternativas; direitos humanos; análise institucional.

\section{THE INSTITUTING POWER IN THE PROJECT "EXERCISING CITIZENSHIP"}

\begin{abstract}
The Penalties and Alternative measures (PAMs) are increasingly used by the Brazilian judiciary system. Given this context, the Sentencing Court of Execution and Alternative Penalties of the Espírito Santo State has established a partnership with the Vitória city hall that offers a training course on Human Rights entitled "Exercising Citizenship" as a way to accomplish the PAMs. This article is the result of a preliminary analysis of a research aiming at analyzing the performance of PAMs in Vitória, with special attention to this training course. The field diary was the main methodological tool, made from experiences in this course from October to November 2010. We were aware of the movements that indicated how the convicted understands / lives / thinks about the PMA, observing the rigid forms, instituted by the execution of the measures, but also - and this is what we try to give visibility - the instituting power of the course.
\end{abstract}

Key words: Alternatives to imprisonment; human rights; institutional analysis.

\section{LA POTENCIA INSTITUYENTE EN EL PROYECTO “EJERCIENDO LA CIUDADANÍA”}

RESUMEN. Las Penas y Medidas Alternativas (PMAs) son cada vez más utilizadas por el sistema jurídico brasileño. En este contexto, el Tribunal de Ejecución de Penas y Medidas Alternativas del Espírito Santo ha establecido un acuerdo con el Ayuntamiento de la ciudad de Vitória, que ofrece un curso de capacitación sobre Derechos Humanos titulado "Ejerciendo la Ciudadanía" como una manera de cumplir con las PMAs. Este artículo es el resultado de un análisis preliminar de una investigación que tiene como objetivo analizar el desempeño de las PMAs en la ciudad de Vitória, con especial atención al curso en cuestión. El diario de campo fue la principal herramienta metodológica, hecho a partir de experiencias en el curso de octubre a noviembre de 2010. Nos pusimos atentos a los movimientos que nos indicaban cómo el apenado entiende/vive/piensa la PMA, observando las formas rígidas, instituidas de realización de las mismas, pero también - y fue a eso que tratamos de dar visibilidad - la potencia instituyente del curso..

Palabras-clave: Penas alternativas; derechos humanos; análisis institucional.

Apoio e Financiamento: Fundo de Apoio à Ciência e Tecnologia de Vitória (ES) FACITEC.

Psicóloga, mestranda em Psicologia Institucional pela Universidade Federal do Espírito Santo, bolsista do Fundo de Apoio à Ciência e Tecnologia - FACITEC.

* Doutora em Psicologia. Professora Adjunta do Departamento de Psicologia e do Programa de Pós-Graduação em Psicologia da Universidade Federal do Espírito Santo. 
Segundo o Ministério da Justiça (2009), no período de janeiro de 2007 a julho de 2008, pela primeira vez no Brasil, o número de cumpridores de penas alternativas ultrapassou o número de pessoas cumprindo penas privativas de liberdade. As Penas e Medidas Alternativas (PMAs) são uma resposta a clamores internacionais pela "humanização" das formas de punição que solicitam a "diminuição da população carcerária, a adoção de alternativas prisionais e a atenção quanto à questão da reinserção social" (Carvalho, 2009, p. 36)

As medidas alternativas caracterizam-se como a suspenção do processo antes do início da instauração criminal, evitando o encarceramento dos indivíduos. Já as penas alternativas são frutos de sentenças, substitutas de penas privativas de liberdade, a pessoas que cometeram crime sem intenção (denominado pelo sistema jurídico de crime culposo) com qualquer pena ou crime doloso (aquele em que há intenção) com pena não superior a quatro anos, sem violência ou grave ameaça, desde que não haja reincidência no mesmo crime. As PMAs configuram-se em: pagamento em dinheiro à vítima ou entidade com destinação social; prestação de outra natureza, como cestas básicas; perda de bens e valores; prestação de serviços à comunidade (PSC); interdição temporária de direitos; limitação de fim de semana; e pena de multa (Brasil, 2009b).

De acordo com o relatório realizado pela Comissão Parlamentar de Inquérito (CPI) do Senado (Brasil, 2009b), as penas alternativas são:

Uma medida punitiva, de caráter educativo e socialmente útil, imposta ao autor da infração penal. $\mathrm{Na}$ verdade, com a pena alternativa não é necessário afastar o indivíduo da sociedade nem excluí-lo do convívio social e familiar e, principalmente, evita-se expor o sentenciado aos males do sistema carcerário (p. 481).

Para o Código Penal, os objetivos principais das Penas e Medidas Alternativas são o nãoencarceramento dos indivíduos, sua reinserção social pelo aspecto socioeducativo da pena e a diminuição de gastos do Estado com o preso (Brasil, 2009b).

O Estado do Espírito Santo, diante de toda essa discussão sobre as penas restritivas de direito (ou PMAs), implantou em Vitória sua primeira Central de Penas e Medidas Alternativas no ano de 2001. Hoje, o município conta com uma Vara de Execução de Penas e Medidas Alternativas (VEPEMA), que é referência para os municípios da Grande Vitória, tendo uma estrutura formada por dois juízes, um setor cartorário, um setor de fiscalização dos prestadores de serviço no cumprimento da Prestação de Serviços a Comunidade
(PSC) e um setor de Serviço Social e de Psicologia. Este tem a função de realizar o acolhimento do apenado, o encaminhamento deste às instituições que o receberão para a PSC (que precisam ser públicas ou sem fins lucrativos), o cadastramento e fiscalização das instituições e o acompanhamento do cumprimento das PMAs.

\section{A PUNIÇÃO AO LONGO DA HISTÓRIA}

Do século XVI ao XVIII, o poder de punir era exercido pela vontade do soberano, que possuía o "direito de apreensão das coisas, do tempo, dos corpos" (Foucault, 1985, p.128) e, inclusive, da vida, que era uma de suas propriedades. A insígnia real era: "causar a morte ou deixar viver" (Foucault, 1985, p. 128) àqueles que o ameaçavam. O poder de morte do príncipe era demonstrado quando ele enviava seus súditos para guerrearem em defesa de seu reino (Junges, 2010) ou quando se vingava de seus inimigos por meio dos suplícios. Essa forma de punição era característica da Sociedade dita Soberana.

Principalmente, pela formação dos Estados Nacionais modernos e a ascensão de uma nova classe, a burguesia, o final do século XVII dispunha-se com outra configuração. E, para organizar sua chegada ao poder, esta classe busca uma tecnologia penal mais eficaz, uma economia do sistema penal (Foucault, 2010). Os reformadores penais pedem o fim das vinganças arbitrárias do príncipe e um remanejamento do poder de punir de forma que ele torne-se mais eficaz, regular e constante (Foucault, 1979). Nesse momento, o poder ${ }^{2}$ busca não mais matar, mas garantira vida. A sociedade disciplinar está nascendo.

Nela, o indivíduo não cessa de passar de um espaço fechado para outro, cada um com seu ritual específico, mas todos com a mesma lógica: disciplinar os corpos tornando-os dóceis e úteis. É em tal sociedade que as instituições de sequestro ${ }^{3}$ emergem, no século XIX, para organizar a massa de indivíduos pobres, decorrentes do processo de industrialização. Tornou-se imprescindível dispor as "coisas", arrumá-

2 Quando Foucault (1985) fala de poder, e falamos com ele neste trabalho, não traz "como conjunto de instituições e aparelhos garantidores da sujeição dos cidadãos em um Estado determinado" (p.88), mas como "multiplicidade de correlações de força imanentes ao domínio onde se exercem e constitutivas de sua organização"(p. 88-89) ou ainda "o nome dado a uma situação estratégica complexa numa sociedade determinada."(p. 89)

3 Foucault (1996) denomina Instituições de sequestro aquelas criadas para vigiar, controlar e normalizar os indivíduos e os grupos. São exemplos desses espaços a fábrica, a escola, o hospital, a prisão, entre outros. 
las para que se pudesse conduzir as condutas, governar. A organização só pode ser efetivada com o assentamento, a fixação dos indivíduos nos estabelecimentos como a fábrica, a escola, o hospital e, em última instância, a prisão. A docilização e desqualificação dos corpos que são disciplinados nessas instituições produzem ao mesmo tempo o aumento da força produtiva e a diminuição da força política, de contestação. A pena de prisão tornou-se a penalidade por excelência da sociedade contemporânea.

Com o passar dos anos, surgem as PMAs que estão localizadas no contexto do que Deleuze (1992) denominou de Sociedade de Controle. Esta trabalha numa lógica disciplinar, mas com o poder atuando, privilegiadamente, de forma contínua, ou seja, não nos livramos dele entre um aparelho e outro, pois sua ação vai além dos dispositivos concretos, como a prisão. $\mathrm{Na}$ Sociedade de Controle, o poder passou a atuar de forma descontínua, intensa, requintada, sofisticada, pelos mais diversos aparatos tecnológicos, atuando cada vez mais ao "ar livre". Com os controles a céu aberto desta Sociedade, os muros da prisão parecem ter dilatado-se, não precisando haver a fixação dos sujeitos em estabelecimentos para sua punição e vigilância.

Como Flores (2009) alerta-nos, as penas alternativas parecem incontestáveis, tendo em vista os horrores vividos nesses anos em que a prisão foi a única forma legal da punição se efetivar. Ao propormos a discussão sobre as PMAs, lembramos do citado autor, quando ele nos aponta que elas parecem estar envoltas em uma "aura humanista", sendo consideradas por muitos como uma "evolução" dos modos de punir. "Envoltos por uma aura humanista, tornam-se [as PMAs] aparentemente incontestáveis. Parecem as únicas críticas ser dos que não admitem qualquer alternativa, que querem maior endurecimento, mais prisões" (Flores, 2009, p. 98).

Deleuze já nos alertava que essa seria uma estratégia da Sociedade de Controle: que acreditemos na crise das instituições e que tenhamos a convicção de que tudo está em reforma (Passetti, 1999). Flores (2009) diz que essas penas parecem ser uma expansão da malha punitiva, numa sociedade que clama por mais (e cada vez mais severas) punições, trazendo inclusive ao judiciário problemas que antes não chegavam.

Autores como Passetti (2006), Flores (2009), entre outros, em consonância com o que trazemos, apontam que vivemos atualmente uma verdadeira "guerra contra o crime", com a implantação e a evocação social de modos cada vez mais duros de punição, além de uma malha punitiva ainda maior, que parece fazer chegar ao Sistema de Justiça pessoas que antes não passariam pelo funil seletor de quem deve cumprir pena (Thompson, 1998).

Vários estudiosos (Passetti, 2006; Geraldini, 2010; Reis, 2010; Flores, 2009) têm mostrado que, por menor que seja o comportamento considerado como criminoso, é necessário encontrar formas de se impedir comportamentos mais graves. Na época dos suplícios, o menor dos criminosos era considerado "um pequeno regicida em potencial" (Foucault, 1979, p. 53); hoje, o movimento aponta para que o "menor" dos criminosos apareça como uma ameaça para toda a sociedade.

Foucault (2010) fala-nos que, na soberania, os ilegalismos populares eram tolerados. Entretanto, esses pequenos delitos tornaram-se visíveis principalmente com a distribuição espacial e social da riqueza em fins do século XVIII, exigindo uma nova forma de controle (Foucault, 1996). Com o passar dos anos, essa malha penal parece ter se estreitado e, atualmente, quase nada mais consegue passar.

\begin{abstract}
A linha direta que havia entre infração e prisão agora é transformada em um fluxo que absorve, expele, modifica e transforma. ... $\mathrm{Na}$ sociedade de controle não há mais a margem, apesar de permanecerem aumentadas as precariedades materiais e imateriais; todos estão dentro (Passetti, 2006, p. 87-88; grifos nossos).
\end{abstract}

Geraldini (2010), ao falar das novas práticas penais (a autora refere-se ao monitoramento eletrônico), aponta que não há fratura no sistema; essas práticas estão menos associadas às ideias reformistas do sistema prisional, do que a soluções que amenizem seus graves problemas, em especial o financeiro. Juridicamente, o que observamos é que aqueles que não cumprem as PMAs, quando estas são impostas como sanções penais, têm como destino a prisão. Dessa forma, as Penas e Medidas Alternativas apoiam-se no sistema prisional como forma de ameaça, necessitando de sua existência.

Isso posto, com o presente artigo, temos o intuito de analisar as PMAs no contexto contemporâneo, momento em que impera a denominada “judicialização da vida”, em que "tudo e todos passaram a ser passíveis de uma resposta jurídica, de uma explicação qualquer a partir dos códigos do Direito, que possa porventura justificar a si e as suas ações" (Reis, 2010, p. 4). No contemporâneo, a autora segue, nossos modos de vida podem ser caracterizados como judicializados (porque revestidos da doutrina do juízo) e judicializantes, com vidas engajadas em formas moralizantes e pouco criativas. A judicialização se dá em defesa de costumes e na busca por verdades, 
e os aparatos judiciários são os únicos considerados legítimos para a resolução do conflito entre as pessoas. Para Passetti (2006), "nesta roda-viva, os cidadãos pouco reparam nas inventivas soluções que eles próprios encontram no dia a dia para resolver as infrações cometidas, e muitas vezes diluem suas atitudes abolicionistas conciliadoras para com a situação-problema..." (p. 91).

Entendemos que o fato de o município de Vitória possuir uma Vara de Execução de PMAs (VEPEMA), a qual tem sido, segundo o Tribunal de Justiça do Espírito Santo, premiada como a segunda melhor do país na área de fiscalização e monitoramento, exige uma análise mais atenta para essa questão e seus efeitos.

Não queremos com essa discussão "desmerecer" as PMAs. Entretanto, o reconhecimento de sua importância não nos deve impedir de problematizá-las. Não podemos perder a dimensão histórica dos fenômenos, das conquistas, pois os processos históricos não são eternos, atualizam-se constantemente (Scheinvar, 2009). Assim, um processo histórico, mesmo quando efetivado em lei, continua se dando, o que significa que nenhum problema se resolve de "uma vez por todas", mas que a reflexão e o embate fazem parte dos movimentos da vida.

Com Veyne (1995), objetivamos “desviar os olhos dos objetos naturais" [as PMAs] para dar visibilidade às práticas, que os objetivaram sob este aspecto datado que apresentam. "Acreditamos, quase que natural e totalmente, que as penas alternativas embora consistam em uma sofisticação máxima do poder punitivo, o flexibilizam, o humanizam, e são o que hoje há de mais progressista no âmbito da Justiça" (Coimbra \& Pedrinha, 2005).

Podemos fazer pela leitura de Scheinvar (2009) um paralelo entre as PMAs e o Estatuto da Criança e do Adolescente (ECA). Ambos foram resultados de lutas, mas não são inovadores por excelência, pois, ao se tornarem lei, também instituem "seus parâmetros de verdade e coerções regulamentadoras que expressam a produção de subjetividades hegemônicas em determinado contexto histórico." (Scheinvar, 2009, p. 72). O ECA, segue a autora, e aqui falamos o mesmo sobre as PMAs, não deveria se apresentar como “...um parâmetro de verdade, mas como uma abordagem que gera a possibilidade de outros olhares para velhas relações, potencializando outras virtualidades" (Scheinvar, 2009, p. 72).

Portanto, questionamo-nos: como estão sendo executadas essas medidas no Estado do Espírito Santo, em especial, na cidade de Vitória? É nessa direção que nosso trabalho se propôs seguir.

\section{CAMINHOS METODOLÓGICOS}

Pretendemos, com esta pesquisa, dar visibilidade às práticas que instituem as PMAs como naturais e eternas, buscando a análise dos sentidos que gradativamente ganham consistência nas práticas, mas que são processos.

Para isso, em nosso percurso, tínhamos sempre ao lado as ferramentas da Análise Institucional francesa. Para ela, instituição não significa o mesmo que organização ou estabelecimento. Trata-se de um conceito-artifício que engloba toda e qualquer relação que se caracteriza por naturalizar práticas, percebendo-as como naturais, eternas e necessárias. Estas podem instrumentalizar-se em estabelecimentos e organizações. As instituições tratam das formas estabelecidas. Toda instituição, porém, tem sempre um lado que a conserva (o instituído) e outro que a contesta e tem a capacidade de criar novas formas (o instituinte). O processo instituinte se refere ao plano de forças que pode culminar na concretização de formas. Essas não são melhores que as anteriores, mas são outras, distintas, diversas. (Altoé, 2004)

No caminho que trilhamos, visitamos à Vepema, realizamos entrevistas com trabalhadores do local e os da Secretaria de Cidadania e Direitos Humanos de Vitória (Semcid), lugares onde acontece um curso de formação em Direitos Humanos que é oferecido aos apenados como uma das formas de cumprimento da PSC. Este curso também foi espaço de nossas investigações e é fruto da parceria entre a Vara de Execuções de PMAs e a Prefeitura Municipal de Vitória (PMV).

Pelas conversas, tanto com os trabalhadores, quanto com os apenados participantes do curso, buscamos problematizar o cotidiano vivido naquele espaço. De maneira complementar, investigamos as PMAs por meio da análise de relatórios, portarias, leis e documentos produzidos.

O diário de campo foi o principal instrumento de construção do corpus de análise, sendo confeccionado pelas vivências institucionais (na Vepema, com os trabalhadores da Semcid e nos cursos de formação oferecidos aos apenados pela PMV). Nele, foram registrados sistematicamente os movimentos cotidianos: o que acontecia, as falas, as perguntas, as sensações. Ficamos atentos aos movimentos que nos indicavam como o apenado ou beneficiário entende/vive/pensa a pena ou medida alternativa por ele executada, nas mudanças que ocorrem em seu cotidiano, no que os trabalhadores que convivem com essas pessoas tinham a dizer, entre outras coisas.

Atentamo-nos, especialmente, ao que se produz corriqueiramente, tentando acompanhar os processos; 
ver o que estava endurecido, as instituições, as formas; mas ver também quais são os pontos de resistência, onde se afirmavam ou ainda se insinuavam outros modos vida, os processos instituintes.

\section{O CAMINHO PERCORRIDO: O PROJETO "EXERCENDO CIDADANIA"}

Em 2008, a Vepema firmou parceria com a Prefeitura Municipal de Vitória (PMV). Da parceria, resultou o projeto intitulado "Exercendo Cidadania", que é coordenado pela Secretaria de Cidadania e Direitos Humanos (Semcid) da PMV.

O projeto "Exercendo Cidadania", em sua primeira etapa, desenvolve um curso básico de Educação em Direitos Humanos, para os apenados selecionados na Vepema que se encaixam em requisitos como disponibilidade de horário e interesse do apenado. O curso é desenvolvido em módulos temáticos por meio de oficinas (de 3 a $6 \mathrm{~h}$ ), contendo atualmente um total de $87 \mathrm{~h}$, sendo $3 \mathrm{~h}$ por noite (das 19 às $22 \mathrm{~h}$ ). Essas horas são descontadas no tempo em que os apenados precisam cumprir na Prestação de Serviço à Comunidade. Na PSC, cada hora de serviço prestado é equivalente a um dia de pena. $\mathrm{O}$ curso tem como objetivo a promoção da educação em direitos humanos e a prestação de serviços nos projetos sociais da PMV (Pinto, 2009).

Busca-se, ainda, por meio da experiência de vida dos sujeitos, além do reconhecimento de seus direitos, a identificação de situações de violação de direitos de seus e, se necessário, o encaminhamento para a rede de proteção social e de direitos humanos (Vitória, 2009b).

Ele conta com a participação de diferentes Secretarias da PMV, por meio de oficinas ministradas por servidores lotados nas gerências que possuem temáticas trabalhadas no projeto (Pinto, 2009), como: Introdução aos Direitos Humanos; Diversidade sexual e prevenção à homofobia; Relações de gênero e violência doméstica; Relações étnico-raciais; Proteção e defesa do direito do consumidor; Mediação de conflitos familiares; Educação para o trânsito; Educação ambiental; Direitos da criança e do adolescente; Direitos da pessoa idosa; Direitos da pessoa com deficiência; Defesa civil; Uso de drogas; Prevenção DST/AIDS; Direito do trabalho; Educação inclusiva; Trabalho e geração de renda, Diversidade religiosa, entre outros (Vitória, 2009a).

Após frequentarem o Curso de Educação em Direitos Humanos, os apenados passam, então, para a segunda parte do projeto (caso tenham mais de $87 \mathrm{~h}$ de PSC para cumprir). Nessa etapa, eles são encaminhados para a Prestação de Serviços à Comunidade em projetos sociais da PMV.

De maio de 2008 a novembro de 2009, foram concluídas seis turmas de Educação em Direitos Humanos. De outubro a novembro de 2010, a $11^{\text {a }}$ turma terminou suas atividades. Até o final de 2010, 213 pessoas concluíram o curso.

\section{A 11' TURMA DO PROJETO "EXERCENDO CIDADANIA": AS SURPRESAS DO CAMINHO}

De outubro a novembro de 2010, todas as noites, de segunda à quinta, das 19 às $22 \mathrm{~h}$, frequentamos o Curso de Formação em Direitos Humanos oferecido pela Semcid aos apenados encaminhados pela Vepema. Na sala, 15 pessoas em média faziam o curso como cumprimento da PSC, com idades entre 24 e 58 anos e, em sua grande maioria, composta de homens (no máximo 3 mulheres frequentavam os grupos).

Eram advogados, professores, feirantes, estudantes, comerciantes, carpinteiros, barmans, auxiliares de serviços gerais, pintores, motoboys, balconistas, agentes da polícia civil... Alguns deles já estiveram presos e a pena alternativa faz parte da progressão de regime; outros têm a sua primeira experiência como apenados.

Sujeitos diferentes, vindos de vários lugares e classes sociais, coloriam o espaço. Quais eram os cenários de nossas noites? Do lado de fora, uma mesa com dois refrigerantes e alguns biscoitos oferecidos pela Vepema era posta para acalmar a fome daqueles que vieram direto do trabalho ou para "forrar" o estômago dos que iriam dali para seu emprego noturno. Na sala, víamos desdentados e engravatados sentados lado a lado discutindo violência doméstica. Víamos um pai, muito jovem, com o filho de aproximadamente três anos, participando da oficina (ele não tinha com quem deixá-lo naquela noite), escutando atento sobre relações de gênero e virando exemplo de que as coisas podem estar mudando. Víamos um marido apenado levando a esposa para frequentar o curso e ambos repensando sobre o tratamento que dispensavam aos doentes mentais. Víamos uma mulher de longos cabelos loiros, barriga de fora e um piercing no umbigo levantando a voz para contestar a facilitadora, porque não concordava com o que ela falava. Víamos uma negra alta, com muitas tatuagens nos braços, dizendo possuir oito filhos e uma neta de dois anos (que precisou deixar com a vizinha de 14 anos, pois a mãe da menina, de 17, está na escola), desconcertando um advogado que "exigia" que os celulares ficassem desligados durante as oficinas. Verdadeiras pinturas se faziam todas as noites naquele lugar, e era bonito de se ver. 
Alguns chegavam ao grupo cansados do trabalho. Outros, às 22h, ao saírem dali, iam trabalhar: um pintor que trabalhava à noite, porque as pessoas reclamavam do cheiro de tinta quando o serviço era feito de dia; um vigilante noturno, que trabalhava das 19 às $7 \mathrm{~h}$ e que, para estar no grupo, precisava pagar alguém para substituí-lo no trabalho. "E sobra algum pro senhor no final do mês tendo que pagar alguém lá?, perguntei. Ah, minha filha, a gente dá um jeito né, faz uns bicos aí... Quem mandou dar mole, né?". Outro saía direto do grupo para preparar as notícias que precisavam chegar antes do café da manhã... E, do jornal que trabalhava, às $7 \mathrm{~h}$ seguia para um supermercado ficando lá até às $15 \mathrm{~h}$.

Fomos "armados" de textos que versavam sobre a ampliação do sistema penal, pensando na docilização como engrenagem do sistema punitivo, preocupadas no quão moralizador poderia ser um curso em Direitos Humanos ministrado para apenados. Surpreendemonos com oficinas dinâmicas, informativas de direitos e deveres, além de problematizadoras de formas de viver instituídas. Os facilitadores, pessoas diferentes a cada dia, com profissões variadas e pertencentes a diversas secretarias da PMV, ministravam as oficinas ${ }^{4}$ e, em sua maioria, ouviam o que aquelas pessoas tinham a dizer e, a partir do cotidiano de cada um, da realidade levada por eles a cada encontro, estratégias eram pensadas por todos para a resolução das dificuldades do dia a dia. Além das temáticas estipuladas, tantas outras coisas que não eram temas das oficinas eram problematizadas. E as discussões, sempre acaloradas! E as falas, sempre provocadoras. "Eita turma empoderada!", dizia uma das facilitadoras.

O ambiente, porém, não se mostrava sempre propício à discussão. Eles reclamavam muito de alguns facilitadores que tentavam impor certas verdades "goela abaixo", não deixando que eles falassem em alguns momentos. Isso se dava por consequência de algumas práticas, tais como: alguns profissionais tinham a preocupação de passar todo o conteúdo programado e, por vezes, precisavam abafar algumas questões trazidas. Eles, por vezes, queixavam-se: "Poxa, larga esses slides e vamos discutir!”. Sugestão que poderia ou não ser aceita, dependendo do facilitador; outros falavam ainda que eles teriam outro momento para discutir sobre determinados tópicos, que seriam temáticas de outras oficinas; algumas vezes, ainda, o corte nos

4 Ao entrarem em contato com o facilitador de determinada Secretaria e conhecerem o cotidiano de trabalho daquele, muitos apenados identificavam-se profissionalmente com o local e descobriam "o que poderiam fazer" na segunda fase do curso, na PSC. comentários dava-se quando estes traziam conteúdos preconceituosos. Neste caso, o corte nas falas era em decorrência de uma postura política de não ouvir o que consideravam como absurdo e usar aquele espaço para afirmar outras coisas, que consideravam mais potentes.

Diante da realidade que se construía com o curso e das discussões realizadas em nosso grupo de pesquisa, fomos convocados a nos desarmar das verdades obtidas por meio da leitura de diversos artigos críticos às PMAs e apostar no processo, tarefa que não foi fácil. Vínhamos em uma linha de raciocínio que pensava as penas alternativas de uma forma bastante crítica antes de entrar em contato com o projeto... Depois, ao frequentar os grupos, fomos ao outro extremo: acabamos romantizando tudo. Deixávamos verdades e nos apoiávamos em outras. Entretanto, precisávamos pensar que não estávamos ali para confirmar nem negar as afirmações dos autores lidos. Como nos alerta Heckert e Passos (2009), não queríamos que nosso objetivo fosse constatar a veracidade das informações na realidade, mas notar como as PMAs estão sendo executadas em Vitória, especificamente, como essas sanções penais efetivavam-se naquele grupo. Precisávamos estar abertos ao que viria e nos desvencilharmos dessas verdades, sem nos apoiarmos em outras... Árdua tarefa!

Nesse ponto, lembramo-nos de Coimbra e Nascimento (2004) quando elas falam do conceito de sobreimplicação da Análise Institucional. Este se refere à uma dificuldade de análise que, mesmo quando é realizada, faz-se isoladamente, considerando apenas um único nível, um objeto ou uma dimensão da instituição. Não havendo análise das multiplicidades, há, de acordo com as autoras, o favorecimento dos processos de institucionalização e, em alguns momentos, em decorrência disso, a interrupção dos processos de transformação. Passávamos, nesse momento, por um processo de sobreimplicação.

Corríamos o risco de nos prendermos à instituição PMAs, não enxergando o movimento sempre presente e, por consequência, a potência instituinte inerente às instituições (que sempre possuem um lado instituído e outro instituinte, que são inseparáveis, como as faces de uma moeda). No curso, essas sanções penais estavam em constante desconstrução e outros territórios eram construídos a cada grupo. Precisávamos estar atentos às porosidades existentes nas PMAs, que permitiam o rompimento de sua forma de ser e a criação de outras, o embaçamento de seus contornos. Nosso trabalho de pesquisa objetivava compor com os movimentos que rompem o instituído, ou seja, movimentos potentes no sentido de afirmação de outras formas de ser e estar no mundo, e foi por aí 
que tentamos nos guiar. Nossa atenção passou a ser atraída pela produção de crise e a construção de práticas mais potentes, mesmo que provisoriamente.

Percebíamos, assim, o alvoroço geral causado quando os profissionais tocavam em verdades endurecidas em cada um de nós durante os grupos. Os comentários de indignação iam para além da sala em que estávamos: corriam o pátio no intervalo com murmurinhos pelos corredores, dirigiam-se conosco para nossos lares e trabalhos, voltavam outro dia na oficina com temática diferente. As convicções foram balançadas. Fazia-se pensar!

\begin{abstract}
Inicia-se mais uma oficina. "Saí daqui ontem pensando... Sabe, o rio só muda seu curso quando o volume de água aumenta", disse um deles. Éramos banhados a cada noite por uma chuva forte e a água batia fortemente nas margens do rio. Umas oficinas reverberavam em outras. Não se esquece o assunto, ele volta, liga-se ao anterior, e as margens sofrem cada dia mais pressão (Diário de campo, 13/10/10).
\end{abstract}

Víamos o quanto os facilitadores tinham que suar para que certas concepções, certas instituições fossem problematizadas. O tema "relações de gênero", por exemplo, numa sala com muitos homens (e com uns dois deles se mostrando muito machistas) e a oficineira mulher, provocou um fervoroso debate sobre a questão. A facilitadora tinha que gritar, que encontrar forças para não ser massacrada. Ela confessou-me, no intervalo: "Trabalhar com essas temáticas em apenas dois dias é muito difícil! Sair da zona de conforto é difícil. Eu fazê-lo perder o trono, de macho dominante, é suado! E falar isso pra ele, que está com a mulher do lado, ofende-o!" (Diário de campo, 05/10/2010).

Outro assunto que gerou muita discussão foi o referente à temática "Diversidade Sexual e Prevenção da Homofobia". A facilitadora iniciou o grupo diferenciando sexo de sexualidade e apontando conceitos que seriam discutidos ao longo do grupo como heterossexual, homossexual, bissexual, gay, lésbica, travesti, transexual, entre outros. Falas de indignação eram ditas a todo o momento expressando a não-conformidade com o que ela trazia: "Somos obrigados a conviver com isso! [com a presença de pessoas homossexuais]" (Diário de campo, 10/11/2010). O principal argumento de nãoconformidade utilizado pelo grupo é a religião. A facilitadora, nesse momento, não discutia (era a estratégia que ela entendia como sendo eficiente no sentido de ser ouvida, de mostrar outra dimensão da questão), não colocava a religião em questão. Ela escutava, atentamente, e logo, em seguida, continuava sua explanação/problematização sem questionar os ideais religiosos que foram expostos pelos membros do grupo, mas dizendo da importância de se repensar alguns conceitos, da violação de direitos civis que aconteciam com as pessoas que possuíam essa orientação sexual, do sofrimento que muitos deles passavam diariamente por causa do preconceito sofrido.

Sempre chegávamos um pouco mais cedo para poder conversar com as pessoas, e um dia tivemos o seguinte diálogo com um dos participantes das oficinas:

\footnotetext{
"Já está na hora de ir embora?", perguntou o rapaz. "Mas, você já quer ir? O grupo de hoje nem começou ainda!", respondi. E ele seguiu: "Eu quero ir embora desde a hora que eu piso aqui, na verdade, desde antes de sair de casa para vir pra cá. Eu não gosto de estar aqui. Não gosto de nada aqui! Nada aqui faz bem pra mim, não era pra eu estar aqui com essas pessoas. Não é que elas sejam más, são pessoas boas, mas já fizeram tantas coisas ruins na vida, já passaram por tantas situações que eu não passei. Eu não gosto daqui" (Diário de campo, 21/10/10).
}

Para nós, que esperávamos um ambiente moralizador, e encontramos um lugar de debate de diferentes temas, de recorrente reconstrução de ideias socialmente difundidas, de informações sobre os direitos humanos, que escolhemos aquele espaço para ser problematizado pela pesquisa, as coisas estavam indo bem. Mas, para essa pessoa, que precisava cumprir apenas 90h e pagar algumas cestas básicas, que provavelmente cometeu, pela quantidade de horas a cumprir, um pequeno delito, a obrigatoriedade daquele espaço era um castigo. Sufocante. Ao longo do grupo, olhávamos para ela e víamos fadiga, inquietação, cansaço. Estávamos no grupo de formas diferentes.

Entretanto, também podemos ver, por meio de sua fala, que o participante acima mencionado não se reconhecia nos outros, achando que sua vida não tinha nada em comum com a vida daquelas pessoas, que não deveria misturar-se "com esse tipo de gente". Ele não conseguia pensar que esse encontro com outro, tão distante de sua realidade, poderia ser potente.

Outro integrante do grupo, certa vez, disse que aquele espaço era bom, mas ele, que tinha um emprego noturno e outro das 7 às $15 \mathrm{~h}$, sentia-se muito cansado e, se pudesse escolher, pagaria sua falta com a sociedade por meio da doação de cestas básicas.

Enquanto para uns "a cruz estava pesada", outros adoravam estar ali e cotidianamente falavam que, 
embora contassem os dias para o término do curso, sentiriam saudades daqueles dias, dos debates, das pessoas que conheceram. Os grupos eram divertidos, em especial depois de um tempo, quando as pessoas já se conheciam melhor. Assim, as coisas passavam a ser mais leves - embora não deixassem de ser, em alguns momentos (in)tensas.

Quando o tema foi Drogadicção, no início do encontro a facilitadora convocou os participantes a falarem de suas experiências com as drogas. E, no decorrer do grupo, ela utiliza-se das experiências dos cursistas para falar sobre o tema, dizendo que o problema com a droga não é a droga em si, mas o tipo de relação que se faz com ela e, assim, as consequências que ela pode trazer para a vida de quem utiliza. Assim, enquanto uns diziam que " $a$ droga foi uma praga em sua vida", outros afirmavam que "o único problema de usar droga é a possibilidade de ser preso, que sua vida não mudou em nada com a droga ou sem a droga, mas já o levou para o presídio e o trouxe até ali, por isso, ele não queria mais isso para sua vida!" (Diário de Campo, 16/11/10). Mais uma vez, as instituições tinham seus contornos embaçados!

Muitos se encontravam na situação do outro e, no intervalo, chamavam o companheiro e conversavam sobre o assunto. Outros, que não passaram pelo que o outro passou, davam força, falavam que estavam ali para o que fosse preciso. Andar junto costuma dar "um gás" para quem possa estar cansado!

Era bonita a mistura que se fazia, o contato de pessoas tão diferentes, que argumentavam, em cada tema, cada um a seu modo, buscando elementos de seu cotidiano e fazendo com que muitos mundos se mostrassem.

Nas oficinas sobre Direitos, muitos dos apenados descobriam que seus direitos estavam sendo violados e pediam informação do que deveriam fazer. "Rapaz, vou começar a exigir meus direitos, que nem isso eu faço!"; "Ih, mais um processo!", era o que se ouvia. Entretanto, enquanto alguns facilitadores apontavam para a importância dessa "tomada de consciência", da busca por direitos como algo positivo, um dos apenados apontava outro aspecto da questão:

É lei pra tudo, hoje! As coisas acontecem, as pessoas vão lá e criam leis, ao invés de reparar e prevenir o que acontece na sociedade. Se aumenta a massa de reclamação, eu não considero isso bom! Significa que alguma coisa está errada na sociedade... é reflexo do social e é lá que temos que resolver o caso, ao invés de atacar as causas com paliativos criando leis e assegurando direitos! (Diário de campo, 18/10/10).
Lembramos de Rolnik (1995), quando ela nos fala que a conquista da democracia e, consequentemente, do estatuto de cidadãos para todos com a garantia de direitos civis, não assegura uma qualidade de vida satisfatória. O importante, por isso, não é somente assegurar direitos, mas afirmar a vida em sua potência criadora, algo que vai para além dos Códigos.

$\mathrm{O}$ ato de pesquisar era colocado em questão a todo o momento. Era claro como as falas do pesquisador eram decorrentes de suas implicações, ou seja, dos lugares que este ocupa diante das instituições (Altoé, 2004). Não somos neutros diante dos assuntos. Alguns mexem mais conosco, deixam-nos inquietos, pois falam de assuntos que estão inscritos fortemente em nossa história, ou porque o lugar que ocupamos nos autoriza a falar sobre, ou por outros motivos. Outros, entretanto, deixam-nos tímidos diante do que é dito. Em uma das oficinas sobre Relações Étnico-raciais, por exemplo, um dos apenados veio perguntar-me o motivo de eu estar tão calada. "Você está quieta assim porque é branca, e esse assunto te intimidou?" (Diário de campo,14/10/10). Essa foi uma intervenção na minha forma de estar naquele grupo daquele momento em diante, fazendo uma análise das minhas implicações. Será que a presença daquele facilitador, homem, negro teria me intimidado? A temática como relação de gênero, que discutia questões como posição social da mulher, desigualdade dela perante o homem, machismo, violência contra mulher, violência familiar me convocavam a falar de maneira mais aberta, menos tímida, do que a do dia. E o fato de um deles ter me chamado a atenção para essa questão foi muito interessante.

Ao longo dos encontros, levávamos um caderno no qual fazíamos breves relatos das principais questões discutidas no grupo, as falas dos participantes, questionamentos trazidos, dúvidas, análises, o que sentíssemos como "digno de nota". No intervalo, deixava-o aberto sobre a mesa para que os participantes do grupo pudessem opinar sobre os escritos, acrescentar algo ou retirar alguma coisa que eles não quisessem que fosse dita em nossa pesquisa. Certo dia, um deles nos disse o seguinte: "você não vai anotar isso que ele disse não? Isso é pra você anotar, porque é muito interessante!”. Assim, os relatos, algumas vezes, eram feitos a muitas mãos.

Pensamos ainda em outro caderno, que fosse usado por eles para que fizessem suas observações sobre o grupo, sobre estar apenado, sobre qualquer coisa que sentissem vontade de escrever. O caderno circulou entre eles e os relatos vieram sob a forma de escrita e desenhos e rendeu muitas perguntas acerca da pesquisa, dos objetivos, do que é um mestrado, do que se espera de uma pesquisa, do que se faz como 
pesquisador, de como se analisa as coisas que se escreve.

Os cadernos mostraram-se como elementos importantes da pesquisa, como personagens daquela história e como elemento permite que a análise aconteça. Neles continham não apenas relatos de histórias (acontecidas nos grupos, nos presídios pelos quais eles passaram, no julgamento, nos mais variados espaços da vida), mas também produção de outras histórias, na medida em que provocavam questões acerca da pesquisa, das PMAs, de suas vidas inseridas nesse contexto.

Problematizava-se, com os cadernos, a ciência que era trazida pelos facilitadores nos encontros como lugar da "sabedoria suprema". Quando ela aparecia, nenhum outro argumento a vencia, o lugar dos outros discursos era reservado ao não-saber, eram desqualificados. Os cadernos, que funcionavam como um vetor instituinte, davam a eles possibilidade de questionar o saber científico, de perguntar sobre seus objetivos e suas funções, percebendo, entre outras coisas, seu processo de construção.

\section{DAS MARCAS QUE FICARAM}

O mundo pode ser, dependendo do geógrafo que o representa, marcado por caminhos dicotômicos, como o das instituições, que, por muitas, vezes visualizamos nessas páginas: penas alternativas ou prisão; curso bem ou mal realizado pelos oficineiros; aqueles que escutam e aqueles que não escutam; o jeito certo e o errado... Essas são algumas das bipolaridades com as quais nos deparamos e que trouxemos para esse trabalho. As dicotomias são peças importantes da engrenagem que faz funcionar esse mundo punitivo que habitamos.

Quando pensamos no curso ou nas outras formas de cumprimento das PMAs, quando elas acontecem sem que se problematize, sem que se reflita o que estamos fazendo de nós mesmos e do mundo, quando elas são apenas o cumprimento do que é estabelecido pelo juiz, há a exposição dessas bipolaridades e a reprodução das instituições. Entretanto, quando há o exercício da reflexão, do pensamento, de pensar sobre a própria vida e como esta está inscrita no social, como, muitas vezes, o curso propiciou, há espaço para o processo instituinte, que propicia a constituição de novas formas de ser e estar no mundo.

Mesmo com tantos estudos que versam sobre as PMAs refereindo-se ao refinamento das formas de punir, dos controles que hoje operam a céu aberto, buscamos neste trabalho dar visibilidade às forças instituintes de efetivação das PMAs, ou seja, aquelas com capacidade de contestação e criação de outras formas, de se fazer justiça, de se relacionar com o outro, de viver e de entender a vida.

\section{REFERÊNCIAS}

Altoé, S. (2004). Objeto e método da análise institucional. In René Lourau: analista institucional em tempo integral (pp. 66-85). São Paulo: Hucitec.

Brasil. (2009a). Código Penal. (15a ed.). São Paulo: Saraiva.

Brasil. (2009b). Congresso Nacional. Câmara dos Deputados. Comissão Parlamentar de Inquérito do Sistema Carcerário. CPI sistema carcerário. Brasília: Câmara dos Deputados, Edições Câmara.

Carvalho, M. W. V. de. (2009). Penas alternativas $e$ histórias de vida: narrativas e encontros com a justiça. (dissertação de mestrado). Universidade Federal Fluminense, RJ.

Coimbra, C., \& Nascimento, M. L. (2004). Sobreimplicação: práticas de esvaziamento político? Niterói: Universidade Federal Fluminense. Recuperado em 14 de dezembro de 2011, de http://www.slab.uff.br/exibetexto2.php?link=.\%2Ftexto $\mathrm{s} \% 2$ Ftexto 22 .htm $\&$ codtexto $=22 \& \operatorname{cod}=22 \& \mathrm{tp}=\mathrm{t} \&$ nome autor .

Coimbra, C., \& Pedrinha, R. D. (2005). Metáforas do controle no século XXI: penas alternativas, justiça terapêutica. Recuperado em 10 novembro de 2010, de http://www.slab.uff.br/exibetexto2.php

Deleuze, G. (1992). Post-scriptum sobre as sociedades de controle. In Conversações (pp. 219-226). Rio de Janeiro: Ed 34.

Flores, D. P. (2009) Penas e medidas alternativas: o brilho de uma pérola à sombra da prisão. In PIVETES: Encontros entre a Psicologia e o Judiciário (pp. 9398). Curitiba: Juruá.

Foucault, M. (1979). Vigiar e punir: nascimento da prisão. Petrópolis: Vozes.

Foucault, M. (1985). Método. In: História da sexualidade I: a vontade de saber (pp. 88-97). Rio de Janeiro: Graal.

Foucault, M. (1996). A verdade e as formas jurídicas. Rio de Janeiro: Nau.

Foucault, M. (2010). A prisão vista por um filósofo Francês. In Ditos e Escritos IV: Estratégia poder-saber (pp. 152-158). (2a ed.). Rio de Janeiro: Forense Universitária.

Geraldini, J. R. (2010). Combater a violência com tecnologia e inteligência: o monitoramento eletrônico como dispositivo de controle no Rio Grande do Sul. [CD-ROM]. In Anais do XI Simpósio Internacional IHU: o (des)governobiopolítico da vida humana. São Leopoldo, RS.

Heckert, A. L. C., \& Passos, E. (2009). Pesquisaintervenção como método, a formação como intervenção In Carvalho, S., Ferigato, S., \& Barros, M. E. B. Conexões: saúde coletiva e políticas da subjetividade (pp. 376-393). São Paulo: Hucitec. 
Junges, J. R. (2010). Agenciamentos comunitários e biopolíticos do direito à saúde. [CD-ROM]. In Anais do XI Simpósio Internacional IHU: o (des)governobiopolítico da vida humana. São Leopoldo, RS.

Ministério da Justiça. (2009). Penas alternativas, soluções para o sistema penitenciário. Recuperado em 30 outubro, de 2010, de http://www.mj.gov.br

Passetti, E. (1999). Sociedade de controle e abolição da punição. São Paulo em Perspectiva, 13(3), 35-46.

Passetti, E. (2006). Ensaio sobre um abolicionismo penal. Verve, 9, 83-114.

Pinto, L. C. (2009). O significado da educação em direitos humanos pelo projeto "Exercendo Cidadania" como novo paradigma de aplicação de Penas Alternativas na Vara de Execução de Penas e Medidas Alternativas VEPEMA. Monografia, Graduação do curso de Serviço Social, Escola Superior de Ciências da Santa Casa de Misericórdia de Vitória (EMESCAM), Espírito Santo.

Reis, E. F. (2010). A judicialização da vida. [CD-ROM] In Anais do XI Simpósio Internacional IHU: o (des)governobiopolitico da vida humana. São Leopoldo, RS.

Rocha, M. L. da, \& Aguiar, K. F. de. (2003). Pesquisaintervenção e a produção de novas análises. Psicologia ciência e profissão, 23 (4), 64-73.

Rolnik, S. (1995). À sombra da cidadania: alteridade, homem da ética e reinvenção da democracia. In
Magalhães, M. C. R. (Org.), Na Sombra da Cidadania (p. 141-170). São Paulo: Escuta.

Scheinvar, E. (2009). O feitiço da política pública: escola, sociedade civil e direitos da criança e do adolescente. Rio de Janeiro: Lamparina, Faperj.

Thompson, A. (1998). O verdadeiro conteúdo do verdadeiro Direito Penal corretivo. In Quem são os criminosos? O crime e o criminoso: entes políticos (pp. 95-125). Rio de Janeiro: Lumen Juris.

Veyne, P. M. (1995). Foucault revoluciona a história. In Como se escreve a história (pp.151-157). (3a ed.). Brasília: Universidade de Brasília.

Vitoria. Secretaria Municipal de Cidadania e Direitos Humanos. (2009a). Plano de Trabalho. (2009). Vitória, out-nov. Disponibilizado pela gerência de políticas de Direitos Humanos.

Vitoria. Secretaria Municipal de Cidadania e Direitos Humanos. (2009b). Relatório de Gestão. (2009). Vitória. Disponibilizado pela gerência de políticas de Direitos Humanos.
Endereço para correspondência:
Fabiana Davel Canal. Rua Manoel Pires Martins, 400, apto 401, Bairro Santo Andrezinho, CEP 29360-000, Castelo-ES, Brasil. E-mail: fabidavel@yahoo.com.br.
Recebido em 03-08-2011

Aceito em 29-10-2012 